\title{
Dopełnienie zbioru rozmytego względem argumentu
}

\section{Complement of a fuzzy set with respect to the argument}

\author{
Piotr Dworniczak \\ KATEDRA MATEMATYKI STOSOWANEJ, UNIWERSYTET EKONOMICZNY W POZNANIU, \\ AL. NIEPODLEGŁOŚCI 10, 60-967 POZNAŃ \\ p.dworniczak@ue.poznan.pl
}

\begin{abstract}
In the paper the concept of complements in the fuzzy environment is presented. The complements are considered in two variants; the complement to the universum and the complement with respect to the argument. The definitions of both form of complements are given. The basic properties of the complements with respect to the argument, rarely noted in the literature, are presented. The simple interpretation of the complement with respect to the argument in the modeling of linguistic variables and their antonyms has been proposed.
\end{abstract}

\section{Wstęp}

W ostatnich latach coraz częściej w różnych dziedzinach wiedzy pojawia się pojęcie zbioru rozmytego oraz logiki rozmytej. Wiąże się to na pewno z postępującą komputeryzacją i koniecznością przetwarzania języka naturalnego na język rozumiany przez maszyny. Jeszcze niedawno wiele dziedzin zdawało się być nie do opanowania przez automatyczne sposoby przetwarzania danych. Obecnie sytuacja ta ulega zmianie. Jest to częściowo zasługą wprowadzenia nowych pojęć i technik. Jedną z nich jest reprezentacja danych za pomocą zbiorów rozmytych i przeprowadzanie wnioskowania opartego na logice rozmytej. W dziedzinach tych potrzebne jest pojęcie dopełnienia (nazywanego także negacją) zbioru rozmytego. Wyróżniane są tu dwa jego rodzaje: dopełnienie względem innego zbioru (zazwyczaj względem przestrzeni, w której określony jest zbiór rozmyty) i dopełnienie względem argumentu. W poniższym artykule przedstawione zostanie pewne uogólnienie drugiego z nich. Zaproponowana także zostanie jego interpretacja. 
Aby w pełni rozumieć poniższy tekst konieczna jest znajomość pewnych pojęć z zakresu teorii zbiorów rozmytych. Najważniejsze podane są w definicjach, inne w przypisach. Sposób ten pozwala na wygodne zapoznanie się z użytymi terminami bez poszukiwania w literaturze, pozwalając jednocześnie, znającemu je czytelnikowi, na ich ominięcie.

Definicja 1. Zbiorem rozmytym $A$ określonym w przestrzeni $\boldsymbol{X}$ nazywamy zbiór

$$
A=\left\{\left(x, \mu_{A}(x)\right): x \in \boldsymbol{X}\right\}
$$

gdzie $\mu_{A}: X \rightarrow[0,1]$ jest tzw. funkcją przynależności zbioru rozmytego $A$.

Wartość $\mu_{A}(x)$ funkcji przynależności jest interpretowana jako stopień $\mathrm{z}$ jakim element $x$ należy do zbioru $A$, przy czym wartość o odpowiada całkowitej nieprzynależności, a 1 pełnej przynależności elementu do zbioru.

\section{Typy dopełnień zbioru rozmytego i ich wła- sności}

Na zbiorach rozmytych wykonuje się działania analogiczne do działań na zbiorach klasycznych. Jednym z tych działań jest dopełnienie zbioru.

Definicja 2. Dopetnieniem $A^{\prime}$ zbioru rozmytego $A$ (do przestrzeni $\boldsymbol{X}$ ) nazywamy zbiór rozmyty o funkcji przynależności $\mu_{A^{\prime}}(x)=1-\mu_{A}(x)$.

Użyta powyżej formuła wprowadzona została przez prekursora teorii zbiorów rozmytych Lotfi $\mathrm{A}$. Zadeha. Nie jest to jednakże jedyny możliwy sposób wyznaczenia dopełnienia zbioru rozmytego. Najogólniej dopełnienie związane jest z pojęciem negacji (w sensie logiki wielowartościowej) dlatego bywa nazywane negacją zbioru rozmytego. Dopełnienie w sposób ogólny określane jest następująco: element $x$ należy do dopełnienia zbioru $A$ gdy nie należy do zbioru $A$ (lub element należy do dopełnienia zbioru $A$ w takim stopniu w jakim nie należy on do $A$ ). Występuje tu negacja zdania „element $x$ należy do $A$ ”.

Wartość logiczna negacji zdania wyznaczona jest przez funkcję negacji $N:[0,1] \rightarrow[0,1]$ spełniającą warunki

1) $N(0)=1, N(1)=0$,

2) $\forall a, b \in[0,1] \quad a \leq b \Rightarrow N(a) \geq N(b)$.

Jeżeli przy tym funkcja $N$ jest ciągła i ściśle malejąca to nazywamy ją negacją ścista.

Jeżeli ścisła negacja jest inwolutywna tzn. zachodzi $N(N(a))=a$ to negację nazywamy negacja silną.

Ponieważ warunki powyższe nie pozwalają na jednoznaczne podanie postaci funkcji $N$ spotyka się różne jej typy.

Najczęściej używana jest negacja określona formułą $N(a)=1-a$, nazywana negacją Łukasiewicza. Jest to negacja silna. 
Przy zastosowaniu dowolnej negacji $N$ możemy otrzymać uogólnioną definicję dopełnienia zbioru rozmytego.

Definicja 3. Dopetnieniem $A^{\prime}$ zbioru rozmytego $A$ (do przestrzeni $\boldsymbol{X}$ ) nazywamy zbiór rozmyty o funkcji przynależności $\mu_{A^{\prime}}(x)=N\left(\mu_{A}(x)\right)$, gdzie $N$ jest dowolną negacją.

W literaturze przedmiotu wyróżniane są negacje parametryczne i nieparametryczne, z tym, że te drugie można uznać za parametryczne przy ustalonej wartości parametru. Podstawowymi negacjami parametrycznymi są negacje Sugeno i Yagera (zob.np. Łachwa 2001).

Definicja 4. Negacja typu Sugeno (lub $\lambda$-dopetnieniem) nazywamy funkcję $N_{\lambda}:[0,1] \rightarrow[0,1]$ określoną formułą

$$
N_{\lambda}(a)=\frac{1-a}{1+\lambda a},
$$

gdzie $\lambda>-1$ jest parametrem określającym „moc negacji”.

Negacja Sugeno jest negacją silną.

Można wyróżnić przypadki szczególne

a) dla $\lambda=0$; $\lambda$-dopełnienie jest klasyczną negacją Łukasiewicza,

b) dla $\lambda \rightarrow-1^{+}$funkcją graniczną jest tzw. negacja minimalna (negacja drastyczna typu I)

$$
N(a)=\left\{\begin{array}{ll}
1 & \operatorname{gdy} a \neq 1 \\
0 & \operatorname{gdy} a=1
\end{array},\right.
$$

c) dla $\lambda \rightarrow \infty$ funkcją graniczną jest tzw. negacja maksymalna (negacja drastyczna typu II)

$$
N(a)=\left\{\begin{array}{ll}
0 & \text { gdy } a \neq 0 \\
1 & \text { gdy } a=0
\end{array} .\right.
$$

Zauważmy, że negacje drastyczne nie są ścisłe ani silne.

Innym rodzajem negacji parametrycznej jest negacja Yagera ( $p$ dopełnienie).

Definicja 5. Negacją typu Yagera (lub p-dopetnieniem) nazywamy funkcję $N_{p}:[0,1] \rightarrow[0,1]$ postaci

$$
N_{p}(a)=\left(1-a^{p}\right)^{\frac{1}{p}}, \quad \text { gdzie } p>0 .
$$

Negacja Yagera jest negacją silną.

W szczególnych przypadkach mamy

a) dla $p=1 ; p$-dopełnienie jest klasyczną negacją Łukasiewicza,

b) dla $p \rightarrow \infty$ funkcją graniczną jest negacja minimalna,

c) dla $p \rightarrow \mathrm{O}^{+}$funkcją graniczną jest negacja maksymalna. 
Drugim typem dopełnienia zbioru rozmytego jest dopełnienie względem argumentu. Pojęcie to wprowadza się dla zbioru rozmytego określonego w podzbiorze przestrzeni liczb rzeczywistych.

Definicja 6. Dopetnieniem względem argumentu zbioru rozmytego $A$ określonego $\mathrm{w}$ przestrzeni $[0,1]$ nazywamy zbiór rozmyty $\neg A$ określony przez funkcję przynależności

$$
\mu_{\neg A}(x)=\mu_{A}(1-x) .
$$

Powyższe określenie, wykorzystujące negację Łukasiewicza, można uogólnić wprowadzając dowolną negację $N$.

Definicja 7. Dopetnieniem względem argumentu zbioru rozmytego $A$ określonego na przestrzeni $[0,1]$ nazywamy zbiór rozmyty $\neg A$ określony przez funkcję przynależności

$$
\mu_{\neg A}(x)=\mu_{A}(N(x)) .
$$

Przy tej definicji spełnione są własności W1)- W7).

W1) Dla dowolnego zbioru rozmytego $A$ i negacji inwolutywnej $N$ zachodzi $\neg(\neg A)=A$.

Uzasadnienie: $\mu_{\neg(\neg A)}(x)=\mu_{\neg A}(N(x))=\mu_{A}(N(N(x)))=\mu_{A}(x)$.

W2) Dla dowolnego zbioru rozmytego $A$ i dowolnej negacji $N$ zachodzi $(\neg A)^{\prime}=\neg\left(A^{\prime}\right)$

Uzasadnienie: $\mu_{(\neg A)^{\prime}}(x)=N\left(\mu_{\neg A}(x)\right)=N\left(\mu_{A}(N(x))\right)=\mu_{A^{\prime}}(N(x))=\mu_{\neg\left(A^{\prime}\right)}(x)$. W3) Dla dowolnego zbioru rozmytego $A$ i negacji ciągłej $N$ zachodzi $\operatorname{hgt}(A)=\operatorname{hgt}(\neg A){ }^{1}$

Uzasadnienie: $\operatorname{hgt}(\neg A)=\sup _{x \in X} \mu \neg A(x)=\sup _{x \in X} \mu_{A}(N(x))=\sup _{N(x) \in X} \mu_{A}(N(x))=$ $\operatorname{hgt}(A)$.

Wniosek z W3) Zbiór $A$ jest normalny ${ }^{2}$ wtedy i tylko wtedy gdy zbiór $\neg A$ (przy negacji ciągłej) jest normalny.

W4) Dla dowolnego zbioru rozmytego $A$ i dowolnej negacji $N$ jeżeli $\forall x \in X \quad \mu_{A}(x)=c=$ const. to $\forall x \in X \quad \mu_{\neg A}(x)=c$.

Wniosek z W4) $A=\varnothing \Leftrightarrow \neg A=\varnothing$ oraz $A=F \Leftrightarrow \neg A=F$, gdzie $\varnothing$ i $F$ są zbiorami rozmytymi (nazywanymi pustym i petnym) określonymi odpowiednio przez stałe funkcje przynależności $\mu_{\varnothing}(x) \equiv 0$ oraz $\mu_{F}(x) \equiv 1$.

W5) Dla dowolnych zbiorów rozmytych $A$ i $B$ i ciągłej negacji $N$ zachodzi

$$
A \subseteq B \Leftrightarrow \neg A \subseteq \neg B .3
$$

\footnotetext{
${ }^{1}$ Liczbę $\operatorname{hgt}(A)=\sup _{x \in X} \mu_{A}(x)$ nazywamy wysokością zbioru rozmytego $A$.

${ }^{2}$ Zbiór rozmyty $A$ nazywamy normalnym $\operatorname{gdy} \operatorname{hgt}(A)=1$.

3 Symbol $\subseteq$ oznacza zawieranie się zbiorów rozmytych. Zbiór rozmyty $A$ zawiera się $\mathrm{w}$ zbiorze rozmytym $B$ gdy $\forall x \in \boldsymbol{X}: \mu_{A}(x) \leq \mu_{B}(x)$.
} 
Uzasadnienie: $A \subseteq B \Leftrightarrow \forall y \in \boldsymbol{X}: \mu_{A}(y) \leq \mu_{B}(y)$.

$$
\begin{aligned}
& \text { Biorąc } y=N(x) \text { otrzymujemy } \\
& \forall N(x) \in \boldsymbol{X}: \mu_{A}(N(x)) \leq \mu_{B}(N(x)) \Leftrightarrow{ }^{*} \\
& \Leftrightarrow^{*} \forall x \in \boldsymbol{X}: \mu_{A}(N(x)) \leq \mu_{B}(N(x)) \Leftrightarrow \neg A \subseteq \neg B .
\end{aligned}
$$

Równoważność oznaczona * wymaga ciągłości negacji $N$.

Wniosek z W5) Dla dowolnych zbiorów rozmytych $A$ i $B$ i ciągłej negacji $N$ jest

$$
A=B \Leftrightarrow \neg A=\neg B .4
$$

W6) Zbiór $A$ jest wypukły 5 wtedy i tylko wtedy gdy zbiór $\neg A$ jest wypukły.

Uzasadnienie $(\Rightarrow): A$ jest wypukły zatem

$$
\mu_{A}\left(\lambda x_{1}+(1-\lambda) x_{2}\right) \geq \min \left\{\mu_{A}\left(x_{1}\right), \mu_{A}\left(x_{2}\right)\right\} .
$$

Przyjmijmy, że $x_{1} \leq x_{2}$.

Z nierówności $\min \left\{x_{1}, x_{2}\right\} \leq \lambda x_{1}+(1-\lambda) x_{2} \leq \max \left\{x_{1}, x_{2}\right\}$, przy $x_{1} \leq \mathrm{x}_{2}$ mamy $x_{1} \leq \lambda x_{1}+(1-\lambda) x_{2} \leq x_{2}$.

Z własności negacji jest $N\left(x_{1}\right) \geq N\left(\lambda x_{1}+(1-\lambda) x_{2}\right) \geq N\left(x_{2}\right)$.

Ponieważ $N\left(\lambda x_{1}+(1-\lambda) x_{2}\right)$ jest punktem pośrednim między $N\left(x_{1}\right)$ i $N\left(x_{2}\right)$, a zbiór $A$ jest wypukły to $\mu_{A}\left(N\left(\lambda x_{1}+(1-\lambda) x_{2}\right)\right) \geq \min \left\{\mu_{A}\left(N\left(x_{1}\right)\right), \mu_{A}\left(N\left(x_{2}\right)\right)\right\}$ czyli $\mu_{\neg A}\left(\lambda x_{1}+(1-\lambda) x_{2}\right) \geq \min \left\{\mu_{\neg A}\left(x_{1}\right), \mu_{\neg A}\left(x_{2}\right)\right\}$.

Zatem zbiór $\neg A$ jest wypukły.

Uzasadnienie $(\Leftarrow)$ jest analogiczne.

Wniosek z W3) i W6) Jeżeli $A$ jest liczbą rozmytą ${ }^{6}$ na przestrzeni $[0,1]$ to $\neg A$ również jest liczbą rozmytą na $[0,1]$.

Dla dopełnienia względem argumentu nie zachodzą prawa de'Morgana. Prawdziwe są natomiast prawa, w pewien sposób analogiczne, podane jako własność W7.

W7) Dla dowolnych zbiorów rozmytych $A$ i $B$ w przestrzeni $\boldsymbol{X}$ i dowolnej tnormy $7 T$ i s-normy $S$ wyznaczających odpowiednio iloczyn i sumę zbiorów rozmytych zachodzi:

4 Zbiór rozmyty $A$ jest równy zbiorowi rozmytemu $B$ (ozn. $A=B$ ) gdy $\forall x \in \boldsymbol{X}: \mu_{A}(x)=\mu_{B}(x)$. 5 Rozmyty podzbiór $A$ przestrzeni $\boldsymbol{R}$ nazywamy wypukłym gdy dla dowolnych $x_{1}, x_{2} \in \boldsymbol{R}$ oraz dowolnego $\lambda \in[0,1]$ zachodzi $\mu_{A}\left(\lambda x_{1}+(1-\lambda) x_{2}\right) \geq \min \left\{\mu_{A}\left(x_{1}\right), \mu_{A}\left(x_{2}\right)\right\}$.

${ }^{6}$ Liczba rozmyta nazywam tu dowolny normalny i wypukły zbiór rozmyty na przestrzeni liczb rzeczywistych o ciągłej funkcji przynależności. W literaturze występują także inne definicje liczby rozmytej.

7 t-normy i s-normy są uogólnieniami koniunkcji i alternatywy. 


$$
\begin{aligned}
& \text { a) } \neg(A \cup B)=\neg A \cup \neg B . \\
& \text { b) } \neg(A \cap B)=\neg A \cap \neg B . \\
& \text { Uzasadnienie: a) } \forall x \in \boldsymbol{X}: \mu_{\neg(A \cup B)}(x)=\mu_{(A \cup B)}(N(x))= \\
& =S\left[\mu_{A}(N(x)), \mu_{B}(N(x))\right]=S\left[\mu_{\neg A}((x)), \mu_{\neg B}((x))\right]=\mu_{(\neg A \cup \neg B)}(x) . \\
& \text { b) } \forall x \in \boldsymbol{X}: \mu_{\neg(A \cap B)}(x)=\mu_{(A \cap B)}(N(x))= \\
& =T\left[\mu_{A}(N(x)), \mu_{B}(N(x))\right]=T\left[\mu_{\neg A}((x)), \mu_{\neg B}((x))\right]=\mu_{(\neg A \cap \neg B)}(x) .
\end{aligned}
$$

Przedstawione powyżej pojęcia stanowią uogólnienie dopełnienia zbioru rozmytego względem argumentu gdy zbiór ten określony jest na przestrzeni [0,1]. W literaturze rzadziej spotkać można dopełnienia zbioru rozmytego względem argumentu w przypadku gdy zbiór określony jest na przedziale $[0, K]$. Dopełnienie względem argumentu określa się wówczas (zob. np. Kacprzyk 2001) przez funkcję przynależności $\mu_{\neg A}(x)=\mu_{A}(K-x)$.

Również to pojęcie można uogólnić wprowadzając dowolną negację (tak jak w Definicji 7), z tym, że wtedy „funkcja negacji” jest określona na przedziale $[0, K]$ o wartościach $\mathrm{w}[0, K]$ natomiast warunek 1 ) negacji przyjmuje postać $N(\mathrm{o})=K \mathrm{i} N(K)=\mathrm{o}$.

Można zmodyfikować negacje Sugeno i Yagera tak aby był spełniony ten warunek. Wszystkie własności przedstawione powyżej dla zbiorów na przestrzeni $[0,1]$ pozostają prawdziwe. Oczywiście można najpierw przedział $[0, K]$ przekształcić do $[0,1]$ za pomocą bijekcji $f:[0, K] \rightarrow[0,1]$ i wówczas wyznaczyć dopełnienie względem argumentu i przenieść je następnie za pomocą funkcji odwrotnej $f^{-1} \mathrm{z}$ powrotem na $[0, K]$. Najprostszą taką bijekcją jest funkcja liniowa $f(t)=\frac{t}{K}$.

W analogiczny sposób postąpić można ze zbiorem rozmytym określonym na dowolnym przedziale domkniętym $[k, K]$. Wtedy liniową bijekcją jest $f(t)$ $=\frac{t-k}{K-k}$.

\section{Interpretacja negacji zbioru rozmytego wzglę dem argumentu}

Powyżej przedstawionej negacji zbioru rozmytego względem argumentu użyć można przy określaniu zmiennych lub wartości lingwistycznych i ich antonimów. W 1975 r. Lotfi Zadeh, w drugiej z serii prac (Zadeh 1975),

Funkcja $T:[0,1] \times[0,1] \rightarrow[0,1]$ nazywana jest $t$ - normą gdy

1) jest niemalejąca względem obu argumentów tzn.

$$
a \leq b \text { i } c \leq d \Rightarrow T(a, c) \leq T(b, d),
$$

2) jest przemienna tzn.

3) jest lączna tzn.

$$
T(a, b)=T(b, a),
$$

$T(T(a, b), c)=T(a, T(b, c))$,

4) spełnia warunek brzegowy

$$
T(a, 1)=a \text {. }
$$

Funkcja $S:[0,1] \times[0,1] \rightarrow[0,1]$ nazywana jest $s$ - norma gdy spełnia warunki 1) 2) i 3) jak powyżej, a ponadto warunek brzegowy 4$) S(a, 0)=a$. 
wprowadził wartość lingwistyczną „prawdziwy” (ang. true) jako zbiór rozmyty na przedziale jednostkowym [o,1]. Funkcję przynależności określił formułą

$$
\mu_{\text {true }}(x)=\left\{\begin{array}{cc}
0 & \text { gdy } x \in[0, a] \\
2\left(\frac{x-a}{1-a}\right)^{2} & \operatorname{gdy} x \in\left[a, \frac{a+1}{2}\right] \\
1-\left(\frac{x-1}{1-a}\right)^{2} & \text { gdy } x \in\left[\frac{a+1}{2}, 1\right]
\end{array}\right.
$$

gdzie $a$ jest pewnym subiektywnym parametrem.

Funkcja przynależności wartości lingwistycznej „fałszywy” (ang.false) określona została jako $\mu_{\text {false }}(x)=\mu_{\text {true }}(1-x)$.

Graficznie funkcje te można przedstawić jak poniżej.

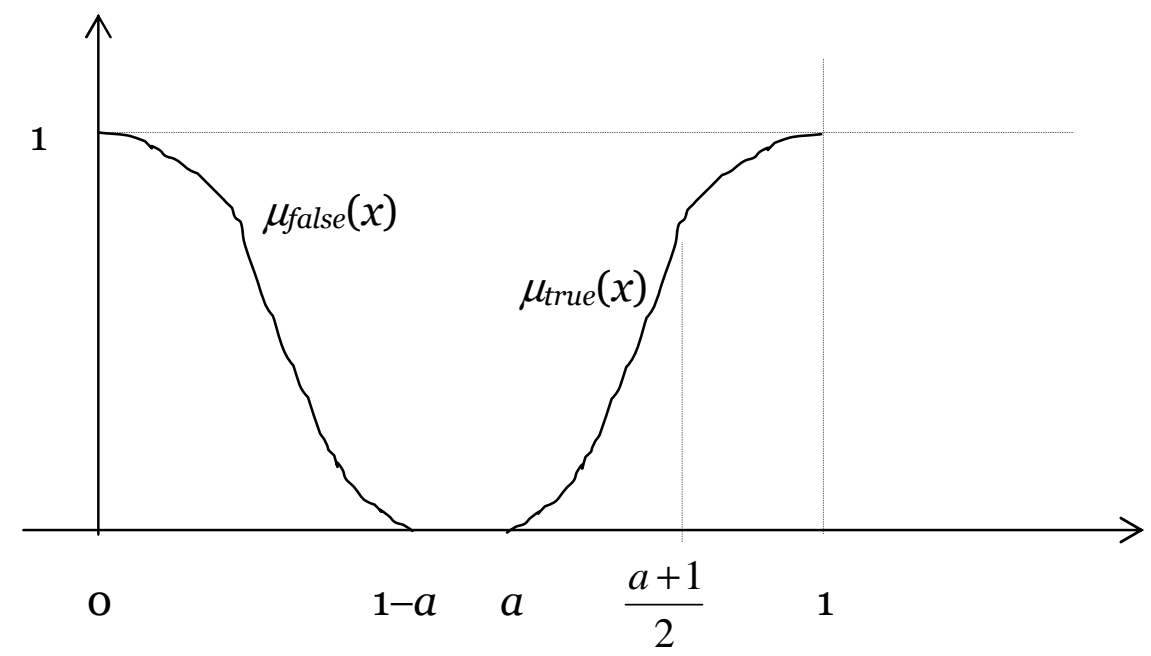

Przy wykorzystaniu dopełnienia względem argumentu regułę tę można rozszerzyć na dowolne określenia antonimiczne.

Określenia antonimiczne rozumieć tutaj należy w klasycznym sensie jako przeciwstawne (antagonistyczne) typu mały - duży, bogaty - biedny, młody - stary, fałszywy - prawdziwy. Są to tzw. antonimy właściwe 8 .

Zauważmy, że rozumienie tego typu związków nie jest równoznaczne z dualizmem między elementami par mały - niemały, bogaty - niebogaty, młody - niemłody. W takim przypadku zasadne wydaje się stosowanie do-

8 Do antonimów zaliczane są również określenia w pewien szczególny sposób kontrastujące ze sobą typu kwadrat - koło, felczer - lekarz, czerwone - czarne, generał - szeregowy te jednak nie będą tu rozważane. Wyrażenia te nazywane są konwersjami (zob. Encyklopedia języka polskiego, 1994, s. 20). Dąbrówka i Geller (2001) podają, że „antonimy modelują stany postrzegane jako niezgodne", natomiast w słowie wstępnym do ich pracy A. Markowski pisze, że „antonimia to - mówiąc najogólniej - językowy sposób wyrażania przeciwieństwa, kontrastu, a szerzej rzecz ujmując, także uzupełnianie się sensów.” 
pełnienia do zbioru (do przestrzeni), lepiej oddającego istotę różnicy między podanymi określeniami. Występuje tu bowiem uzupełnianie się sensów obu określeń wyczerpujących w sumie cały zakres danej własności czy nazwy. W językoznawstwie pary te nazywane są antonimami komplementarnymi, gdyż zaprzeczenie jednego elementu pary implikuje stwierdzenie wystąpienia drugiego.

Oczywiście jest tak, że semantyczne określenia antonimiczne wyrażone przymiotnikami dotyczą tych samych obiektów (rzeczywistych bądź abstrakcyjnych) (Nowy stownik poprawnej polszczyzny, 2002, s. 1617). Są zatem określone są na tej samej przestrzeni. W szczególności przestrzenią tą (lub bijektywnym jej obrazem) może być odcinek [0,1]. Dla łatwiejszego skorzystania z negacji względem argumentu na przestrzeni $[0,1]$ dobrze jest brać pod uwagę wyłącznie antonimy przymiotnikowe, dla nich bowiem najłatwiej wyznaczyć zbiór rozmyty i jego dopełnienie będące odzwierciedleniami natężenia danej cechy. Naturalne uporządkowanie liczb na odcinku $[0,1]$ można łatwo powiązać ze stopniowaniem przymiotników. Można powiedzieć, że antonimy przymiotnikowe nazywają lub określają 'dwa krańce' jakiejś cechy lub własności. Krańce te mogą być utożsamiane z wartościami o i 1 lub z „dużą" i „małą” liczbą rozmytą określoną na [0,1]. Zauważmy, że właściwe antonimy przymiotnikowe mogą przy użyciu logiki wielowartościowej być przypisane danemu obiektowi jednocześnie. Dwuwartościowa logika sytuację taką wyklucza. O ile obiektowi można przypisać jedno z określeń pary antonimów to wyłącznie jedno. Albo, albo. Tertium non datur. W warunkach logiki wielowartościowej dopuszczalne jest orzekanie o stopniu spełnienia dwóch przeciwstawnych własności. Obiekt może mieć zatem (w pewnym stopniu) cechę (własność) jak i cechę przeciwną.

\section{Podsumowanie}

Przetwarzanie rozmyte i teoria sterowania rozmytego są w dalszym ciągu obszarem zainteresowań zarówno badaczy teoretyków jak i inżynierów wprowadzających teorię do praktyki. W wielu dziedzinach wdrażane są coraz to nowe rozwiązania.

Również przedstawione uogólnienie dopełnienia względem argumentu może być wykorzystane $\mathrm{w}$ zastosowaniach praktycznych $\mathrm{w}$ różnych dziedzinach. Podstawowym obszarem zastosowań będzie zapewne przeszukiwanie baz danych (Internetu). Tak samo jak w innych przypadkach stosowania zbiorów rozmytych pojawia się pytanie o sposób i sensowność działania. Często bardzo ważne są wtedy opinie ekspertów. Nawet wyznaczenie konkretnej postaci negacji do konkretnego przypadku jest raczej sztuką niż postępowaniem schematycznym. Co ciekawe, mimo wątpliwości, nawet na rynku produktów detalicznych spotkać można urządzenia wykorzystujące logikę i sterowanie rozmyte. Napis fuzzy logic znaleźć można choćby na kamerach video lub pralkach.

Odpowiedzi na pytania dotyczące praktycznych zastosowań mogą znaleźć tylko praktycy-specjaliści w danej dziedzinie ustalający reprezentacje i reguły przetwarzania informacji. 


\section{Cytowana literatura}

Dąbrówka A., Geller E., 2001. Stownik antonimów. Warszawa.

Urbańczyk St. (red.), 1994. Encyklopedia języka polskiego. Wrocław.

Kacprzyk J., 2001. Wieloetapowe sterowanie rozmyte. Warszawa.

Łachwa A., 2001. Rozmyty świat zbiorów, liczb, relacji, faktów, regut i decyzji. Warszawa.

Markowski A. (red.), 2002. Nowy stownik poprawnej polszczyzny PWN. Warszawa.

Zadeh L.A., 1975. The concept of a linguistic variable and its application to approximate reasoning $I$. Information Sciences 8, 199-249.

Zadeh L.A., 1975. The concept of a linguistic variable and its application to approximate reasoning II. Information Sciences 8, 301-357.

Zadeh L.A., 1975. The concept of a linguistic variable and its application to approximate reasoning III. Information Sciences 9, 43-80. 